\title{
Response to: Comment on "Gut Microbiota as a Driver of Inflammation in Nonalcoholic Fatty Liver Disease"
}

\author{
Stefano Bibbò $\left(\mathbb{D},{ }^{1}\right.$ Maria Pina Dore $\mathbb{D}^{1},{ }^{1}$ and Giovanni Cammarota $\mathbb{D}^{2}$ \\ ${ }^{1}$ Department of Clinical, Surgical and Experimental Sciences, University of Sassari, Sassari, Italy \\ ${ }^{2}$ Department of Gastroenterology, Catholic University, School of Medicine and Surgery, A. Gemelli Hospital, Rome, Italy
}

Correspondence should be addressed to Giovanni Cammarota; giovanni.cammarota@unicatt.it

Received 27 June 2018; Accepted 4 July 2018; Published 19 August 2018

Academic Editor: Shin-ichi Yokota

Copyright (c) 2018 Stefano Bibbò et al. This is an open access article distributed under the Creative Commons Attribution License, which permits unrestricted use, distribution, and reproduction in any medium, provided the original work is properly cited.

We would like to thank $\mathrm{Li}$ and Yuan for their insightful comments [1] on our article [2]. The authors focused on the role played by gut microbiota in the pathways of nonalcoholic fatty liver disease (NAFLD) and proposed that the modulation of intestinal dysbiosis may alter the progression of the disease. We agree with this suggestion; indeed, several studies reported the beneficial effect of gut microbiota modulation on NAFLD patients. Studies published in the last year demonstrated that the administration of multistrain probiotic mixtures improved clinical outcomes in overweight patients with NAFLD, normalization of markers of a chronic systemic inflammatory state [3], or the shift towards a normal pattern of fecal gut microbiota [4]. Furthermore, therapeutic modulation of gut microbiota has also proved to be effective in lean patients with NAFLD [5], maybe suggesting a role for gut microbiota independent of adiposity.

Finally, fecal microbiota transplantation (FMT) was also considered a therapeutic tool in NAFLD. Very intriguing results were reported in a trial in mice, showing the reduction of intrahepatic fatty accumulation and of proinflammatory cytokines [6]. Unfortunately, to date, evidence on the beneficial effects of FMT on humans is lacking.

In conclusion, we hope that gut microbiota modulation will be considered a therapeutic tool in patients with NAFLD, but more studies are needed.

\section{Conflicts of Interest}

The authors declare that there is no conflict of interest regarding the publication of this paper.

\section{References}

[1] X. Li and F. L. Yuan, "Comment on "Gut microbiota as a driver of inflammation in nonalcoholic fatty liver disease"," Mediators of Inflammation, vol. 2018, Article ID 3746509, 2 pages, 2018.

[2] S. Bibbò, G. Ianiro, M. P. Dore et al., "Gut microbiota as a driver of inflammation in nonalcoholic fatty liver disease," Mediators of Inflammation, vol. 2018, Article ID 9321643, 7 pages, 2018.

[3] N. Kobyliak, L. Abenavoli, G. Mykhalchyshyn et al., "A multi-strain probiotic reduces the fatty liver index, cytokines and aminotransferase levels in NAFLD patients: evidence from a randomized clinical trial," Journal of Gastrointestinal and Liver Diseases, vol. 27, no. 1, pp. 4149, 2018.

[4] E. Manzhalii, O. Virchenko, T. Falalyeyeva, T. Beregova, and W. Stremmel, "Treatment efficacy of a probiotic preparation for non-alcoholic steatohepatitis: a pilot trial," Journal of Digestive Diseases, vol. 18, no. 12, pp. 698-703, 2017. 
[5] F. Mofidi, H. Poustchi, Z. Yari et al., "Synbiotic supplementation in lean patients with non-alcoholic fatty liver disease: a pilot, randomised, double-blind, placebo-controlled, clinical trial," British Journal of Nutrition, vol. 117, no. 5, pp. 662668, 2017.

[6] D. Zhou, Q. Pan, F. Shen et al., "Total fecal microbiota transplantation alleviates high-fat diet-induced steatohepatitis in mice via beneficial regulation of gut microbiota," Scientific Reports, vol. 7, no. 1, p. 1529, 2017. 


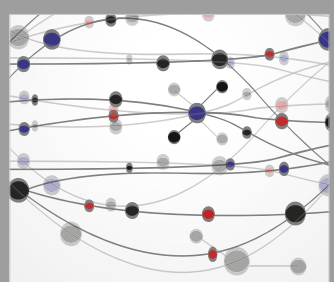

The Scientific World Journal
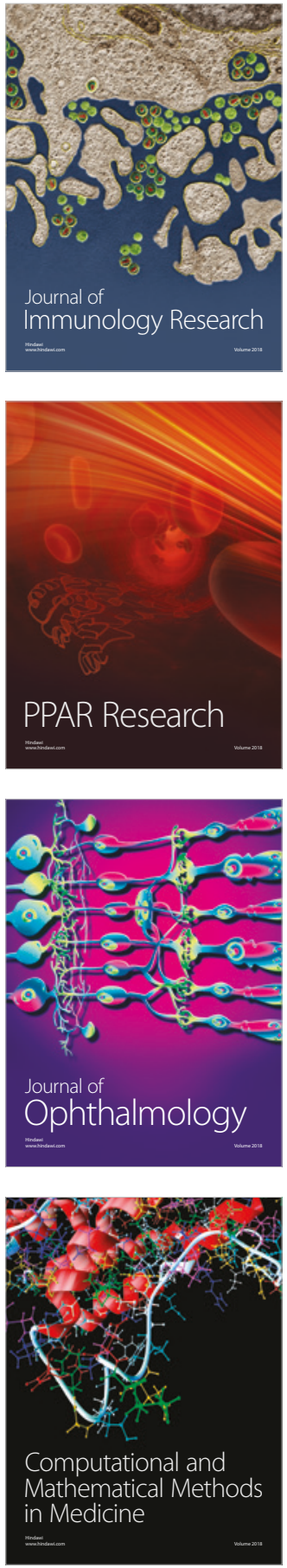

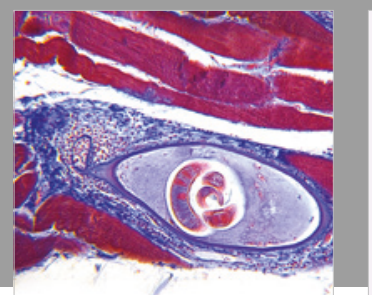

Gastroenterology Research and Practice

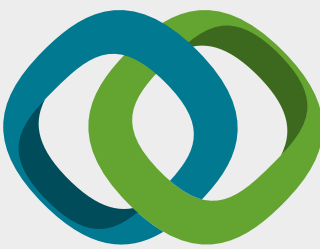

\section{Hindawi}

Submit your manuscripts at

www.hindawi.com
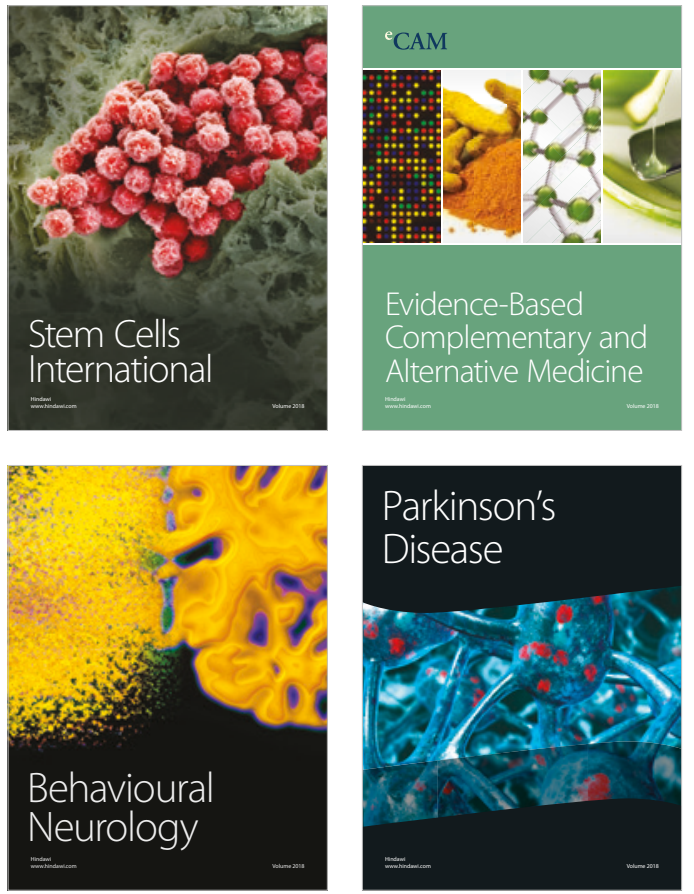

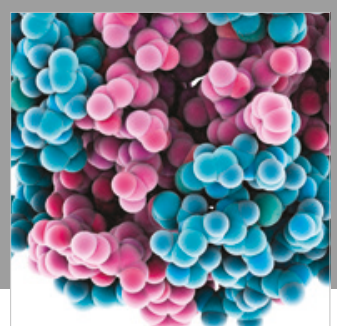

ournal of

Diabetes Research

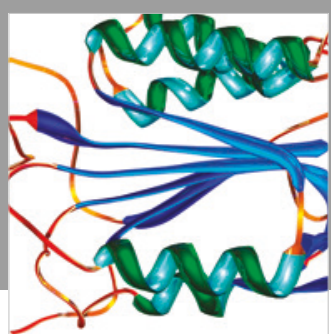

Disease Markers
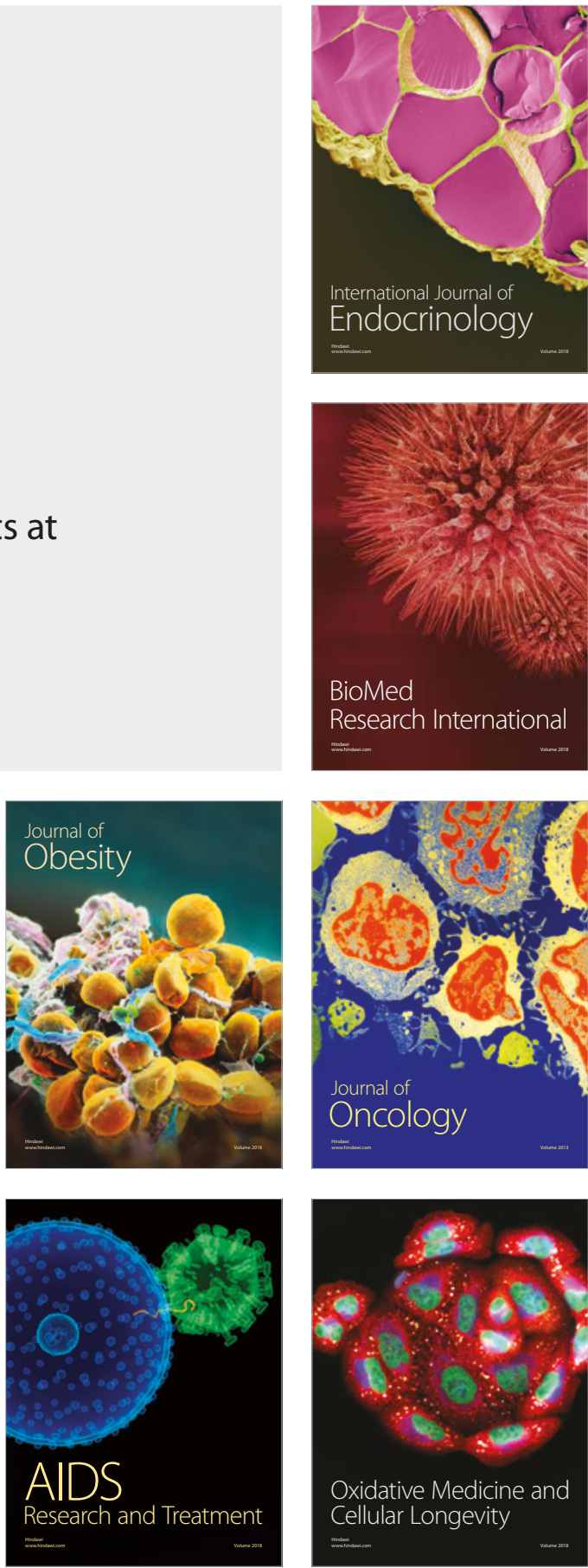